\title{
Real-life experience of quality of life, treatment satisfaction, and adherence in patients receiving oral anticoagulants for atrial fibrillation
}

This article was published in the following Dove Press journal:

Patient Preference and Adherence

\author{
Michaël Benzimra' \\ Béatrix Bonnamour ${ }^{\prime}$ \\ Martin Duracinsky ${ }^{2}$ \\ Christophe Lalanne ${ }^{2}$ \\ Jean-Pierre Aubert ${ }^{2,3}$ \\ Olivier Chassany 2,3 \\ Isabelle Aubin-Auger ${ }^{2,3}$ \\ Isabelle Mahé ${ }^{1,2}$ \\ 'Internal Medicine Department, \\ Hôpital Louis Mourier, APHP, \\ Colombes, France; ${ }^{2}$ Méthodologies et \\ Société (REMES) EA 7334, Recherche \\ Clinique Ville-hôpital, Université Paris \\ Diderot, Sorbonne Paris Cité, Paris, \\ France; ${ }^{3}$ General Medicine Deparment, \\ Université Paris 7, Paris, France
}

Correspondence: Isabelle Mahé Service de Médecine Interne, Hôpital Louis Mourier APHP, I 78 rue des Renouillers, 92700 Colombes, France

Tel +33 | 47606490

Fax +33 | 4760649 |

Email isabelle.mahe@aphp.fr
Introduction: Direct oral anticoagulants (DOACs) have shown noninferiority to vitamin $\mathrm{K}$ antagonists (VKA) in stroke prevention in patients with atrial fibrillation. DOAC treatment may be less demanding than VKA, improving quality of life. To date, there have been no studies of the real-life experience of outpatients receiving anticoagulation therapy for atrial fibrillation in France.

Methods: An observational descriptive real-life epidemiological study used three validated questionnaires (EQ-5D, PACT-Q2, and MMAS-8 French Translation) to assess quality of life, treatment satisfaction, and adherence, respectively, in 200 patients managed on an outpatient basis for atrial fibrillation who were receiving anticoagulation therapy by VKA or DOAC for at least 3 months. Patients were distributed between four groups: primary VKA (P-VKA), switch from VKA to DOAC (S-DOAC), primary DOAC (P-DOAC), and switch from DOAC to VKA (S-VKA).

Results: Two hundred patients responded to the questionnaires: 89, 50, 52, and 9 in the P-VKA, $\mathrm{S}-\mathrm{DOAC}, \mathrm{P}-\mathrm{DOAC}$ and S-VKA groups, respectively. Only the first three groups were compared statistically, because of the small size of the S-VKA group. Quality of life and satisfaction were good in all three groups, with no significant difference in quality of life but significantly greater satisfaction with respect to the "convenience" and "satisfaction" dimensions for DOACs (S-DOAC and P-DOAC groups versus P-VKA group; $p<0.001$, for both dimensions). Adherence did not significantly differ between groups.

Conclusion: The experience of patients under oral anticoagulation therapy for atrial fibrillation managed on an outpatient basis was good, with comparable quality of life under DOACs and VKA, and significantly greater satisfaction under DOACs, without impact on adherence. Taking account of patient preference in "shared decision-making" for the choice of type of anticoagulant could improve the patients' experience of treatment.

Keywords: atrial fibrillation, direct oral anticoagulants, vitamin $\mathrm{K}$ antagonists, satisfaction, adherence, quality of life

\section{Introduction}

Atrial fibrillation (AF) is the most frequent cardiac rhythm disorder, ${ }^{1}$ and an independent risk factor for embolism, increasing the risk of stroke and systemic embolism fivefold. ${ }^{2}$ Stroke is more often recurrent, disabling, and fatal in case of AF. ${ }^{3,4}$

Vitamin $\mathrm{K}$ antagonists (VKA) were until recently the only reference anticoagulants for the prevention of thromboembolism in AF. ${ }^{5}$ The practical difficulties of VKA (narrow therapeutic window, need for biological surveillance, and numerous drug and food interactions) led to the development of direct oral anticoagulants (DOACs) to improve patients' quality of life. DOACs may be less demanding for 
both patient and physician: they do not require regular biological surveillance, they show few drug and food interactions, and the dosage is fixed. In phase III trials, they demonstrated noninferiority to VKA in terms of efficacy and tolerance in preventing stroke and systemic embolism in non-valvular AF. ${ }^{6-9}$

Only a few studies have compared quality of life between DOAC and VKA, in patients recruited in clinical trials or in hospital. ${ }^{10,11} \mathrm{AF}$, however, is in fact followed up on an outpatient basis. ${ }^{12}$ To our knowledge, no studies have assessed the real-life experience of AF patients undergoing anticoagulation therapy. Estimating the quality of life partially addresses this issue, but in a generic manner.

The objective of the present study was to assess the real-life experience of patients taking oral anticoagulants (DOAC or VKA) for non-valvular atrial fibrillation (NVAF) on three complementary parameters that have never been assessed simultaneously: quality of life, treatment satisfaction, and adherence.

\section{Materials and methods Type of study}

Real-life observational descriptive cross-sectional epidemiological study.

\section{Study population}

Between June 2013 and November 2015, telephone numbers were collected for consecutive NVAF patients at various recruitment sites in the Paris region of France (Ile-de-France) so as to have a representative sample of outpatients receiving anticoagulation therapy for AF. Recruitment was performed by five community general practitioners, four community cardiologists, five hospital cardiology departments, one pharmacy, and one emergency department (where the presenting symptom was unrelated to $\mathrm{AF}$ ). Inclusion criteria comprised: patient with NVAF, aged $\geq 18$ years, receiving VKA or DOAC (dabigatran, rivaroxaban, or apixaban) as oral anticoagulation therapy for at least 3 months, speaking and understanding French, and managed on an outpatient basis. Patients were included after they provided oral consent to participate in the study. Exclusion criteria comprised: patient not speaking French, with cognitive or neuropsychiatric disorder, or declining to participate.

\section{Patient groups}

The choice of anticoagulation agent was made by the patient's physician, and was unaffected by study participation. Patients were distributed between four groups according to oral anticoagulation treatment: primary VKA group (P-VKA), taking VKA for at least 3 months, naive to DOAC; S-DOAC, switch from VKA to DOAC for at least 3 months; P-DOAC, taking DOAC for at least 3 months, naive to VKA; and S-VKA, switch from DOAC to VKA for at least 3 months.

\section{Questionnaires}

The experience of patients with AF treated with oral anticoagulants was assessed on three patient-reported outcomes (quality of life, satisfaction with anticoagulation therapy, and adherence) on three questionnaires with validated French-language versions: EuroQol 5-Dimensions 3-Levels (EQ-5D-3L) visual analog scale (VAS), ${ }^{13}$ Perception of AntiCoagulant Treatment Questionnaire 2 (PACT-Q2) ${ }^{14}$ and 8-item Morisky Medication Adherence Scale (MMAS-8). ${ }^{15}$ These questionnaires provided patient-reported outcomes, which are appropriate and, indeed, essential evaluation criteria to assess real-life experience.

The EQ-5D-3L questionnaire is a generic questionnaire, not specific to any particular pathology, measuring healthrelated quality of life. It is simple and quick to administer. It comprises five dimensions: mobility, self-care, usual activities, pain/discomfort, and anxiety/depression. For each dimension, there are three levels of response: no problems, some or moderate problems, or extreme problems.

It is completed by a subjective quality of life score, from 0 to 100 , using a visual analog scale; as this was not possible by telephone, the patient was asked "How would you rate your health today, from 0 to 100 , where 0 is the worst imaginable state of health and 100 the best?".

The PACT-Q assesses the patient's satisfaction with anticoagulation treatment. It comprises two parts, PACT-Q1 and PACT-Q2, and has been validated for AF. ${ }^{16}$ PACT-Q1 assesses expectations ahead of treatment initiation, and PACT-Q2 assesses convenience, burden, and satisfaction with ongoing anticoagulation therapy. As, in the present study, inclusion was after 3 months on oral anticoagulation therapy, only PACT-Q2 was implemented. It comprises three domains with 20 items in all: convenience (11 items: "B"), burden of disease and treatment (two items: "C"), and anticoagulant treatment satisfaction (seven items: "D"). For each domain, there are five response levels: "not at all", "a little", "moderately", "a lot", and "extremely". Two scores are derived from the responses: a convenience dimension score, combining the $\mathrm{B}$ and $\mathrm{C}$ items, and a satisfaction dimension score based on the $\mathrm{D}$ items.

As DOACs show no interaction with food, question B5 (Difficulty avoiding certain foods while taking an anticoagulant treatment) was not appropriate for the DOAC and 
S-DOAC groups, for whom it was replaced by "Is it difficult for you to take your tablet during meals, as recommended?"

The MMAS-8 French translation was used to assess adherence to anticoagulation treatment. It is a recent version of the four-item Morisky scale, ${ }^{17}$ originally intended to assess adherence to antihypertension treatment. ${ }^{15,18,19}$ This questionnaire was validated for VKA therapy. ${ }^{20}$ Seven of the eight items are yes/no questions, and the eighth is scored on five levels. Three categories are derived from the total score: poorly adherent (score $<6 / 8)$, moderately adherent $(6-<8 / 8)$, and highly adherent (score 8/8).

\section{Data collection}

All patients were contacted directly by telephone. Oral consent to participate in the study was collected. Questionnaires were systematically administered in the same order and in the same way. Two physicians conducted the telephone survey. Questionnaire administration was timed, without the patient being informed of this. The following demographic data were also collected: age, gender, date of initiation of any anticoagulation treatment for AF, date of initiation of the current anticoagulant, reason for and date of any switch in anticoagulant if the patient was administered at least two different classes of anticoagulants, specialty of prescribing physician, specialty of physician assuring follow-up, any associated antiplatelet treatment, and medical history for thromboembolic risk scoring on $\mathrm{CHADS}_{2}$ score and $\mathrm{CHA}_{2} \mathrm{DS}_{2}-\mathrm{VASc}$ score and bleeding risk on HAS-BLED score. ${ }^{1}$

The study protocol (2016/45NI) received institutional review board approval (CPP Ile de France IV, $\mathrm{n}^{\circ}$ IRB 00003835) as a non-interventional study.

\section{Statistical analysis}

As this was a descriptive observational study, sample size was primarily based on being able to show significant differences between two groups on the self-reported questionnaires (EQ-5D VAS, 12-point difference; PACT-Q2, 6 points; satisfaction scale, 6 points), and the 8 -item Morisky Medication Adherence Scale (MMAS-8) (8 points). We anticipated that a sample size of 200 patients divided into the four groups and with complete data would allow sufficient power to detect significant differences between groups.

Baseline characteristics were expressed as percentages for qualitative variables and mean \pm standard deviation for quantitative variables. Data for the P-VKA, P-DOAC, and $\mathrm{S}$-DOAC groups were compared using a chi-square test for ordered categorical variables (proportional odds model) for EQ-5D responses and on non-parametric ANOVA (Kruskal-
Wallis) for VAS, PACT-Q2, and MMAS-8 French translation responses, to analyze the impact of qualitative variables on a quantitative variable. Correlation tests were then applied to test associations between the three parameters.

\section{Results}

Between June 2013 and November 2015, 273 patients were contacted and 200 were included (Figure 1). All included patients responded to all three questionnaires, in a mean $18 \pm 6$ minutes. Table 1 shows population characteristics. In the present study, patients had been under anticoagulation therapy for a mean duration of 4 (SD 4.5) years duration.

\section{Reasons for switching}

In the $\mathrm{S}-\mathrm{DOAC}$ group $(\mathrm{N}=50)$, reasons for switching from VKA to DOAC comprised: convenience of DOAC treatment and avoiding blood tests $(50 \% ; \mathrm{N}=25)$, fluctuating international normalized ratio (INR) under VKA (44\%; $\mathrm{N}=22)$, VKA interaction with food ( $4 \% ; N=2)$, and not known $(2 \% ; N=1)$.

In the $\mathrm{S}-\mathrm{VKA}$ group $(\mathrm{N}=9)$, reasons for switching from DOAC to VKA comprised: coronary stenting (33\%; $N=3)$, DOAC side effects $(22 \% ; \mathrm{N}=2)$, severe kidney failure $(11 \%$; $\mathrm{N}=1)$, lack of antidote under DOAC $(11 \% ; \mathrm{N}=1)$, lack of coagulation surveillance under DOAC $(11 \% ; \mathrm{N}=1)$, and not known $(11 \% ; \mathrm{N}=1)$.

\section{S-VKA group}

The S-VKA group was too small for statistical purposes, and comparisons were, therefore, restricted to the P-VKA, P-DOAC, and S-DOAC groups.

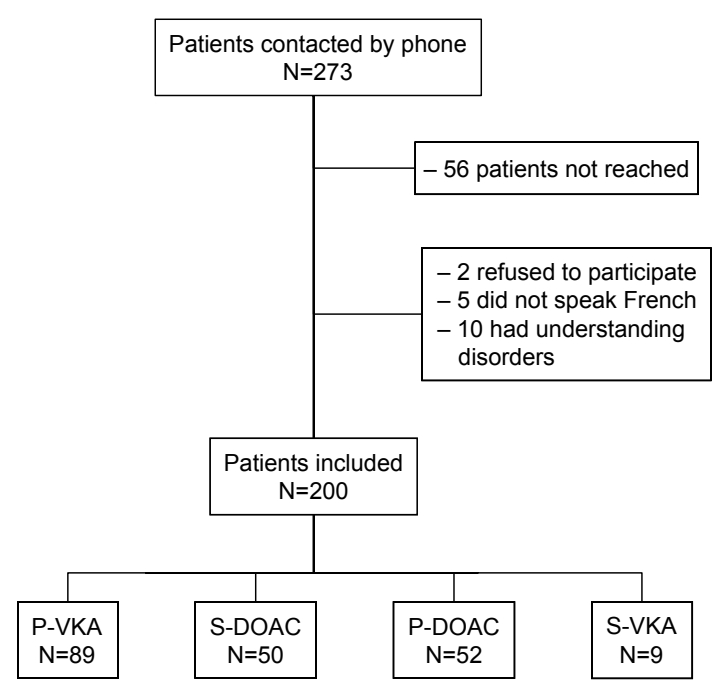

Figure I Flowchart showing patient disposition.

Abbreviations: DOAC, direct oral anticoagulant; P-DOAC, primary DOAC; P-VKA, primary VKA; S-DOAC, switch from VKA to DOAC; S-VKA. switch from DOAC to VKA; VKA, vitamin $K$ antagonists. 
Table I Patient characteristics

\begin{tabular}{|c|c|c|c|c|c|c|c|}
\hline Characteristics & $\begin{array}{l}\text { Patients } \\
\text { (n) }\end{array}$ & $\begin{array}{l}\text { P-VKA } \\
(n=89)\end{array}$ & $\begin{array}{l}\text { S-DOAC } \\
(n=50)\end{array}$ & $\begin{array}{l}\text { P-DOAC } \\
(n=52)\end{array}$ & $\begin{array}{l}\text { S-VKA } \\
(n=9)\end{array}$ & $\begin{array}{l}\text { All patients } \\
(\mathbf{N}=\mathbf{2 0 0})\end{array}$ & $p$-value \\
\hline Age, years: mean (SD) & 200 & $75.7(10.1)$ & $75.8(10.6)$ & $71.3(8.3)$ & $69.3(12.3)$ & $74.3(10.1)$ & 0.004 \\
\hline Gender male: \% & 200 & 52 & 62 & 65 & 67 & 59 & 0.36 \\
\hline $\mathrm{CHADS}_{2}:$ mean $(\mathrm{SD})$ & 200 & $2.07(1.22)$ & $1.88(1.10)$ & I.3I (0.83) & $2.00(1.12)$ & $1.8(1.13)$ & 0.002 \\
\hline $\mathrm{CHA}_{2} \mathrm{DS}_{2}-\mathrm{VASc}$ : mean (SD) & 200 & $3.4(1.6)$ & $3.2(1.5)$ & $2.4(1.3)$ & $2.8(1.6)$ & $3.1(1.53)$ & 0.001 \\
\hline HAS-BLED: mean (SD) & 148 & $2.04(0.96)$ & $2.08(1.10)$ & NT & $\mathrm{I} .78(1.30)$ & $2.03(1.03)$ & 0.69 \\
\hline Antiplatelet therapy: \% & 200 & 13 & 14 & 21 & 33 & 17 & 0.32 \\
\hline Oral anticoagulant prescriber is cardiologist: \% & 200 & 97 & 86 & 100 & 89 & 96 & NT \\
\hline Referent physician of follow-up is GP: \% & 200 & 55 & 24 & 15 & 0 & 34 & NT \\
\hline Actual OACT $<$ I year $(\%)$ & & 15 & 62 & 54 & 75 & 40 & NT \\
\hline Actual OACT $>$ I year $(\%)$ & & 85 & 38 & 46 & 25 & 60 & NT \\
\hline Global OACT (years): mean (SD) & & $6.7(5.5)$ & $2.0(0.8)$ & I.8 (I.I) & $0.8(I . I)$ & $4.0(4.5)$ & 0.15 \\
\hline
\end{tabular}

Abbreviations: DOAC, direct oral anticoagulant; GP, general practitioner; NT, not tested; OACT, oral anticoagulant therapy; P-DOAC, primary DOAC; P-VKA, primary VKA; S-DOAC, switch from VKA to DOAC; S-VKA. switch from DOAC to VKA; VKA, vitamin K antagonists.

\section{Health-related quality of life}

In each domain (mobility, self-care, usual activities, pain/ discomfort, and anxiety/depression) and each group (P-VKA, P-DOAC, S-DOAC), reported problems were usually moderate and rarely extreme (Table 2).

EQ-5D VAS scores were high in all three groups: identical between P-VKA and S-DOAC (65 16$)$, and higher in P-DOAC (69 \pm 17$)$. The ANOVA test on VAS scores found no significant difference between groups $(p=0.290)$.

The P-VKA group more often had moderate or extreme problems than the P-DOAC and S-DOAC groups in all domains except "pain/discomfort" (Figure 2). More than half (60\%) of the S-DOAC patients had moderate or extreme pain or discomfort, compared to $47 \%$ in the P-VKA group and $35 \%$ in the P-DOAC group. Quality of life was better in the P-DOAC group, with less frequent moderate or extreme problems than in the P-VKA or S-DOAC groups in all domains except "self-care".
More than $80 \%$ of patients in each group had no problem with self-care. On the other hand, more than half, overall, reported moderate or extreme anxiety/depression $(58 \%$ in P-VKA, including 10\% extreme; $56 \%$ in S-DOAC, including $6 \%$ extreme).

Overall, quality of life on the EQ-5D-VAS tended to be better in the P-DOAC group, although not significantly.

\section{Satisfaction with anticoagulation treatment}

On average, patients receiving AVK or AOD got a 91/100 convenience score and a 77/100 satisfaction score. More than $85 \%$ of patients, whether receiving VKA or DOAC, had very good convenience scores, and more than $60 \%$ had good overall satisfaction scores. Convenience and satisfaction scores were high in all three groups (Table 3); overall, convenience scores were higher than satisfaction scores (Figure 3).

Table 2 EQ-5D-3L VAS scores by group

\begin{tabular}{|c|c|c|c|c|}
\hline Dimension of the score & $\begin{array}{l}\text { P-VKA } \\
(n=89)\end{array}$ & $\begin{array}{l}\text { S-DOAC } \\
(n=50)\end{array}$ & $\begin{array}{l}\text { P-DOAC } \\
(n=52)\end{array}$ & $\begin{array}{l}\text { Statistical test, } \\
\text { p-value }\end{array}$ \\
\hline \multicolumn{5}{|l|}{ Mobility } \\
\hline No problems & $46 \%$ & $56 \%$ & $67 \%$ & \multirow[t]{2}{*}{ Chi-2=6.I, $p=0.47^{a}$} \\
\hline Moderate/extreme problems & $54 \%$ & $44 \%$ & $33 \%$ & \\
\hline \multicolumn{5}{|l|}{ Self-care } \\
\hline No problems & $82 \%$ & $90 \%$ & $88 \%$ & \multirow[t]{2}{*}{ Chi-2=2.I, $p=0.35^{\mathrm{a}}$} \\
\hline Moderate/extreme problems & $18 \%$ & $10 \%$ & $12 \%$ & \\
\hline \multicolumn{5}{|l|}{ Usual activities } \\
\hline No problems & $69 \%$ & $74 \%$ & $75 \%$ & \multirow[t]{2}{*}{ Chi-2 $=0.85, p=0.66^{\mathrm{a}}$} \\
\hline Moderate/extreme problems & $31 \%$ & $26 \%$ & $25 \%$ & \\
\hline \multicolumn{5}{|l|}{ Pain/discomfort } \\
\hline No problems & $53 \%$ & $40 \%$ & $65 \%$ & \multirow[t]{2}{*}{ Chi-2=6.7, $p=0.036^{\mathrm{a}}$} \\
\hline Moderate/extreme problems & $47 \%$ & $60 \%$ & $35 \%$ & \\
\hline \multicolumn{5}{|l|}{ Anxiety/depression } \\
\hline No problems & $42 \%$ & $44 \%$ & $56 \%$ & \multirow[t]{2}{*}{ Chi-2 $=2.8, p=0.25^{\mathrm{a}}$} \\
\hline Moderate/extreme problems & $58 \%$ & $56 \%$ & $44 \%$ & \\
\hline VAS: mean score (SD) & $65(16)$ & $69(17)$ & $65(16)$ & $F_{2,188}=1.3, p=0.29^{b}$ \\
\hline
\end{tabular}

Notes: aProportional odds likelihood ratio test; 'Kruskal-Wallis test.

Abbreviations: DOAC, direct oral anticoagulant; EQ-5D-3L, EuroQol 5-Dimensions 3-Levels; P-DOAC, primary DOAC; P-VKA, primary VKA; S-DOAC, switch from VKA to DOAC; VAS, visual analog scale; VKA, vitamin K antagonists. 


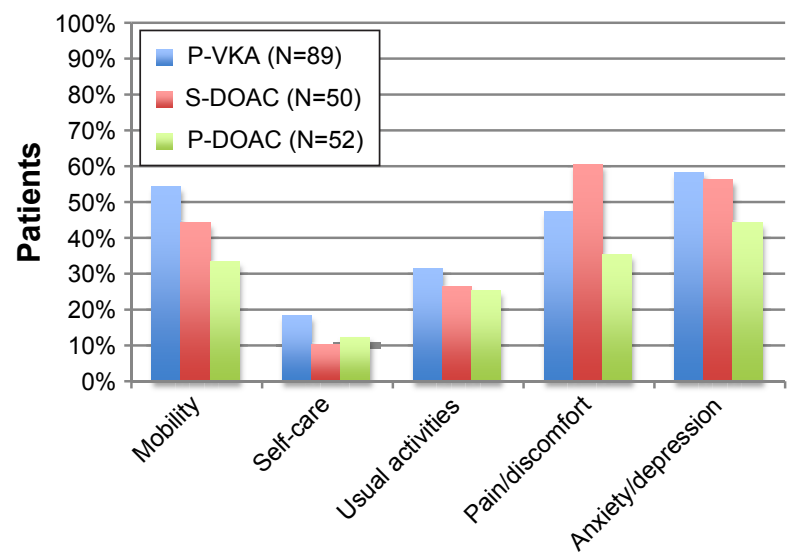

Figure 2 Distribution of patients with any problem (moderate or extreme) over time, for each of the EQ-5D dimensions.

Abbreviations: DOAC, direct oral anticoagulant; EQ-5D, EuroQol 5-Dimensions; P-DOAC, primary DOAC; P-VKA, primary VKA; S-DOAC, switch from VKA to DOAC; VKA, vitamin $\mathrm{K}$ antagonists.

There was a significant difference between the three groups in favor of DOAC for both scores. Post hoc Wilcoxon test revealed that the P-DOAC and S-DOAC groups scored significantly higher than the P-VKA group for satisfaction and convenience $(p<0.001$ for both), without difference between the P-DOAC and S-DOAC groups $(p=0.82$ and $p=0.21$, for convenience and satisfaction, respectively).

\section{Adherence to treatment}

Morisky final scores showed high adherence (score $8 / 8$ ) in more than two-thirds of patients: $70 \%$ for P-VKA, $68 \%$ for S-DOAC, and $71 \%$ for P-DOAC (Figure 4).

Adherence was moderate (scores of 6 or $<8$ ) in $28 \%$ of P-VKA patients, $30 \%$ of S-DOAC patients, and $23 \%$ of P-DOAC patients. Low scores $(<6 / 8)$ were rare: $2 \%$ for P-VKA and S-DOAC, and $6 \%$ for P-DOAC.

There was no significant difference between groups $(p=0.72)$.

\section{Correlation tests}

Correlation tests found no significant associations between the three parameters (quality of life, satisfaction and adherence) $(p>0.05)$.

\section{Discussion}

Real-life DOAC risk/benefit studies reported reassuring data, ${ }^{21-24}$ and concordant findings from phase III clinical trials. ${ }^{25}$ The present study provides new results on the real-life experience of AF patients under anticoagulants, in terms of three parameters (quality of life, treatment satisfaction, and adherence) assessed on validated questionnaires. Outpatients receiving anticoagulation therapy for AF reported good quality of life whatever the form of treatment, with a trend toward better scores for primary DOAC. Satisfaction with anticoagulation treatment was high overall, and significantly better in patients receiving DOAC than VKA in terms of convenience and general satisfaction. Adherence was similar in all three groups and maximal for two-thirds of patients in each group.

\section{Population characteristics}

Mean age was 74.3 years and about half of the subjects (61\%) were over 75 years of age. There was male predominance $(59 \%)$. This population was thus older than in the GARFIELD, ${ }^{22}$ GLORIA, ${ }^{23}$ and PREFER registries, ${ }^{24,26}$ and noninferiority trials. ${ }^{26}$ Thromboembolic and hemorrhagic risk was comparable to the results of published studies. ${ }^{21,26-29}$ Patients in the P-DOAC group were younger than those in the P-VKA group; it may be that physicians tend to prescribe DOACs for younger patients because of lack of experience and follow-up for these molecules in elderly patients with multiple pathologies.

A cardiologist was, according to the patients' reports, the initial prescriber of anticoagulants in $96 \%$ of cases, and assured follow-up in $70 \%$, with general practitioners assuring follow-up in only $30 \%$ of cases. In another French study of AF patients, a cardiologist was the initial prescriber in $78 \%$ of cases, with general practitioners assuring INR follow-up in $80 \%{ }^{29}$ It might be thought that patients in the present study had more cardiologic follow-up than the general population, but it is in fact more likely that follow-up was, in some cases, dual (cardiologist and general practitioner) - without the patient being aware of the fact, especially as INR is often tracked by phone; patients tended to associate their heart condition with the relevant specialist (cardiologist).

Table 3 PACT-Q2 scores by group

\begin{tabular}{|c|c|c|c|c|}
\hline Dimension of the score & $\begin{array}{l}\text { P-VKA } \\
\mathrm{N}=89\end{array}$ & $\begin{array}{l}\text { S-DOAC } \\
\mathbf{N}=\mathbf{5 0}\end{array}$ & $\begin{array}{l}\text { P-DOAC } \\
\mathrm{N}=52\end{array}$ & $\begin{array}{l}\text { Statistical test }{ }^{\mathrm{a}} \text {, } \\
p \text {-value }\end{array}$ \\
\hline Convenience score: mean score (SD) & $87(13)$ & $95(6)$ & $96(5)$ & $F_{2,188}=22, p<0.001$ \\
\hline Satisfaction score: mean score (SD) & $62(11)$ & $74(14)$ & $70(13)$ & $F_{2,188}=20, p<0.001$ \\
\hline Total: mean score (SD) & $83(7)$ & $90(5)$ & $89(5)$ & $F_{2,188}=39, p<0.001$ \\
\hline
\end{tabular}

Note: ${ }^{a}$ Kruskal-Wallis test.

Abbreviations: DOAC, direct oral anticoagulant; PACT-Q2, Perception of AntiCoagulant Treatment Questionnaire 2; P-DOAC, primary DOAC; P-VKA, primary VKA; S-DOAC, switch from VKA to DOAC; VKA, vitamin K antagonists. 


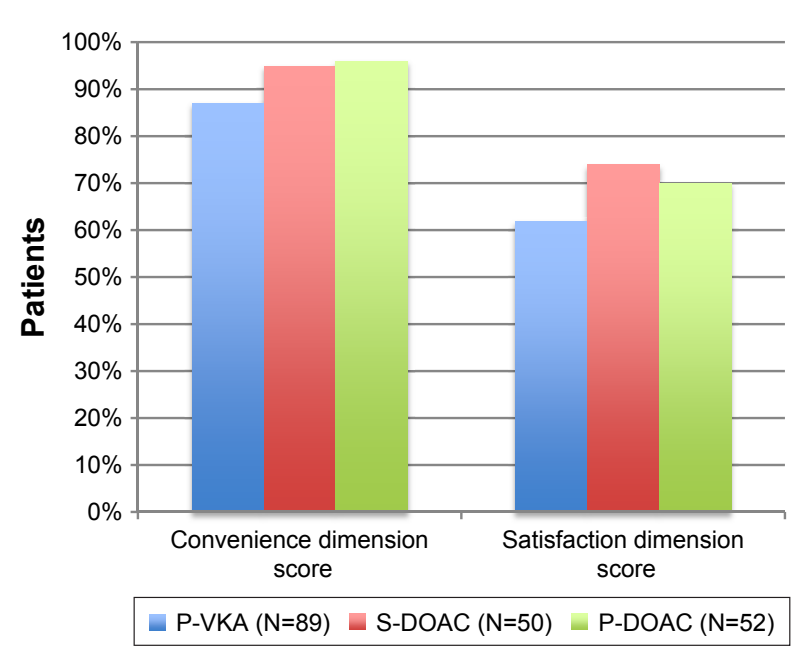

Figure 3 Convenience and satisfaction dimension scores.

Abbreviations: DOAC, direct oral anticoagulant; P-DOAC, primary DOAC; P-VKA, primary VKA; S-DOAC, switch from VKA to DOAC; VKA, vitamin $\mathrm{K}$ antagonists.

\section{Questionnaires}

We choose the quality life generic EUROQOLEQ-5D questionnaire. Indeed it was used in numerous studies, particularly for patients with AF. Because it was a generic questionnaire, we added a specific satisfaction questionnaire for patients under anticoagulant and an adherence questionnaire to capture patients' experience.

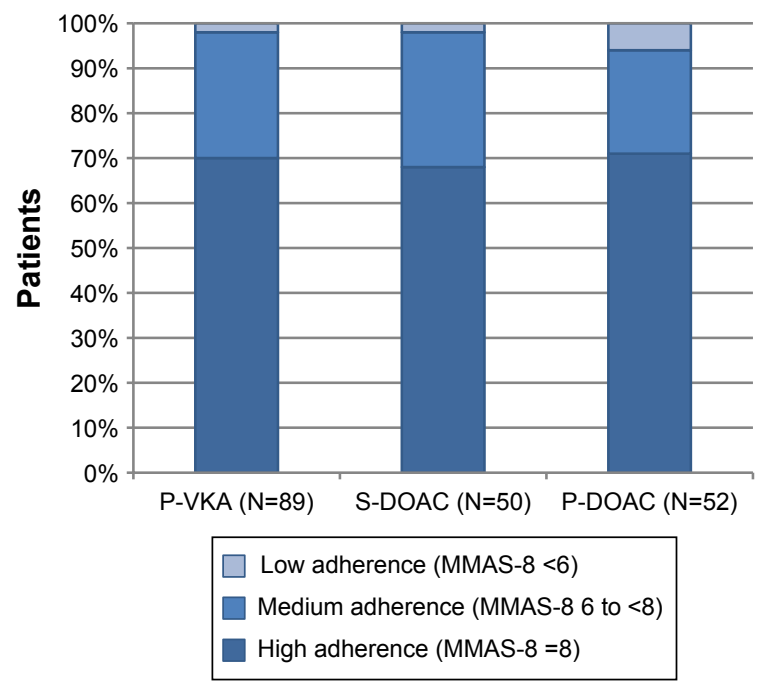

Figure 4 MMAS-8 French translation scores: distribution of patients according to adherence.

Note: The MMAS (8-item) content, names, and trademarks are protected by US copyright and trademark laws. Permission for use of the scale and its coding is required. A license agreement is available from Donald E. Morisky, ScD, ScM, MSPH, I4725 NE 20th St Bellevue, WA 98007, USA; dmorisky@gmail.com.

Abbreviations: DOAC, direct oral anticoagulant; MMAS-8, Morisky Medication Adherence Scale; P-DOAC, primary DOAC; P-VKA, primary VKA; S-DOAC, switch from VKA to DOAC; VKA, vitamin $\mathrm{K}$ antagonists.
Our study includes 33 items, which took up some amount of time to be submitted to our targeted audience and was a real obstacle to getting a large sample of patients.

\section{Health-related quality of life}

In the present study, after at least 3 months of anticoagulation treatment, quality of life on the EQ-5D-VAS questionnaire was good, with a trend toward being better in the P-DOAC group. These findings are similar to those in the literature, where there is no significant difference in quality of life between VKA and DOAC after the initial anticoagulation phase. In AF patients in the RELY trial, followed up for 1 year, ${ }^{10} \mathrm{EQ}-5 \mathrm{D}$ quality of life scores (per dimension and VAS) at 0,3 , and 12 months did not significantly differ between dabigatran and VKA groups. The VAS scores were close to those in the present study: mean, 66/100 for the present three groups, and 70/100 in the RELY trial; and quality of life was stable over the 12 months of follow-up.

In 2014, a Spanish study compared quality of life under DOAC and VKA on the Sawicki questionnaire at 0 and 6 months in patients from the CARDIOVERSE study. ${ }^{11}$ The questionnaire comprised five dimensions and 32 items. Quality of life was initially poorer under VKA, but the difference resolved by 6 months; it may have been due to the greater number of consultations required at initiation of VKA therapy. Independent factors associated with quality of life comprised: greater age, greater left ventricular ejection fraction (LVEF), and DOAC therapy.

Likewise, Marvig's European study of quality of life on the EQ-5D questionnaire at 0 and 3 months in patients with deep venous thrombosis or AF who treated with VKA confirmed this pattern: ${ }^{30}$ quality of life was initially poorer under VKA then improved by 3 months. In the present study, patients had been under anticoagulation therapy for approximately 3 years.

In the present study, convenience scores were very high, for both VKA and DOAC, with an overall mean of 92, and 87, 96, and 95 for the P-VKA, P-DOAC, and S-DOAC groups, respectively. Satisfaction scores were lower, with an overall mean of 67 and group means of 62, 70, and 74, respectively. The better satisfaction found in the P-DOAC and S-DOAC groups did not, however, correlate with better quality of life, which probably depends on a wide variety of factors.

The present convenience and satisfaction scores were comparable to those of the European PREFER-AF registry, ${ }^{26}$ which collected information on satisfaction with anticoagulation therapy and AF patient characteristics in real life. 
The PACT-Q2 satisfaction questionnaire was filled out by 2,985 patients, divided into four groups (no anticoagulant or antiplatelet, VKA, DOAC, and VKA + antiplatelet): mean convenience score was 84 (compared to 92 in the present study) and mean satisfaction score 65 (compared to 67). Unlike in the present study, there was no difference in convenience or satisfaction between patients undergoing VKA or DOAC.

\section{Adherence to treatment}

The ease of using DOACs would suggest better adherence in the P-DOAC and S-DOAC groups compared to VKA, but this was not what emerged in the present study. Adherence was strictly comparable in all three groups. Overall, it was maximum for more than two-thirds of patients in each group and moderate or low for approximately one-third. These results were comparable to those reported by a Canadian anticoagulation clinic, where adherence assessed on the fouritem Morisky questionnaire was similar in patients receiving VKA or DOAC for AF or deep venous thrombosis. ${ }^{31}$

Various factors affect adherence, possibly related to cognition but also to physical, functional, and psychological status and outside influences. In Horstmann's European study, ${ }^{32} 94 \%$ of patients were receiving oral anticoagulants for 12 months post-stroke. Unexpectedly, physical and functional problems, more than cognitive performance, were associated with discontinuation of anticoagulant therapy at 12 months; adherence tended to be better under DOAC than under VKA.

It is, however, difficult to assess adherence objectively. There may have been a selection bias in the present study, as patients with cognitive disorder were excluded for reasons of feasibility (ability to respond orally to the questionnaires).

A review of the literature on factors affecting adherence to warfarin treatment for venous thromboembolic disease and $\mathrm{AF}$ and the impact of warfarin on quality of life found a moderate negative impact of warfarin on quality of life, but with great individual variation in the experience of patients receiving VKA. ${ }^{33}$ Interestingly, in clinical trials comparing adherence between anticoagulants and an alternative such as aspirin, rates of treatment interruption were not higher for VKA than in the control arm.

\section{Impact of the study}

Patient-reported experience of oral anticoagulation therapy has not previously been assessed in real life for AF, although follow-up is mainly on an outpatient basis, and DOACs were specifically developed to improve patients' everyday life by circumventing the heavy demands of VKA treatment. Considering the characteristics of the two classes (VKA and DOAC), we had expected the results to be strongly in favor of DOAC; however, this was not the case. Satisfaction with treatment was indeed better with DOAC (S-DOAC vs P-VKA, $p<0.001$; P-DOAC vs P-VKA, $p<0.001$, for both convenience and satisfaction), but was actually very good in all three groups, with a convenience score of $87 / 100$ under VKA. Moreover, the level of satisfaction did not correlate with quality of life or with adherence, which were both good in all groups, at least after 3 months of anticoagulation therapy. Thus, the theoretic advantages of DOAC do not in themselves determine the patient's experience and, therefore, should not in themselves be a criterion for preferring DOAC to VKA.

The importance of the physician-patient relationship should not be neglected, especially for its impact on the patient's feelings, perception, and experience of the anticoagulation therapy. Communication between physician and patient helps improve and resolve the choice of anticoagulant. ${ }^{34}$

Palacio et al's study of AF outpatients in Florida showed that $85 \%$ expressed a real wish to be involved in the choice of anticoagulation treatment. ${ }^{35}$ They preferred an anticoagulant, first of all, with antidote (36\%), then with better quality of life (26\%), and, finally, with lowest risk of stroke (5\%). This shows that physicians and patients have differing visions of benefits and risks. Patients give greater weight to the risk of hemorrhage than to the risks inherent to the underlying pathology. Their preferences are, thus, different from those of their physician, and are to be taken into account in choosing the anticoagulant. This choice is ultimately up to the patient, after discussion with the physician: each has their own specific expectations, which cannot be generalized. VKA and DOAC have demonstrated comparable efficacy and tolerance, and the patient's personal values, lifestyle, and beliefs are crucial factors determining therapy selection. The role of the physician is to provide good-quality information to the patient regarding the pros and cons of each form of treatment, so as to help the patient in making the choice. This is the "shared decision" process described by Doctors France Légaré and Holly Witteman. Its three key elements comprise: recognizing that a decision is needed, knowing and understanding the best scientific information available, and including the patient's preferences and values in the treatment decision. This model optimally respects the patient's psychology and autonomy, enabling rational choice. ${ }^{36}$ The choice of the most appropriate treatment is a decision to be shared between patient and physician, which 


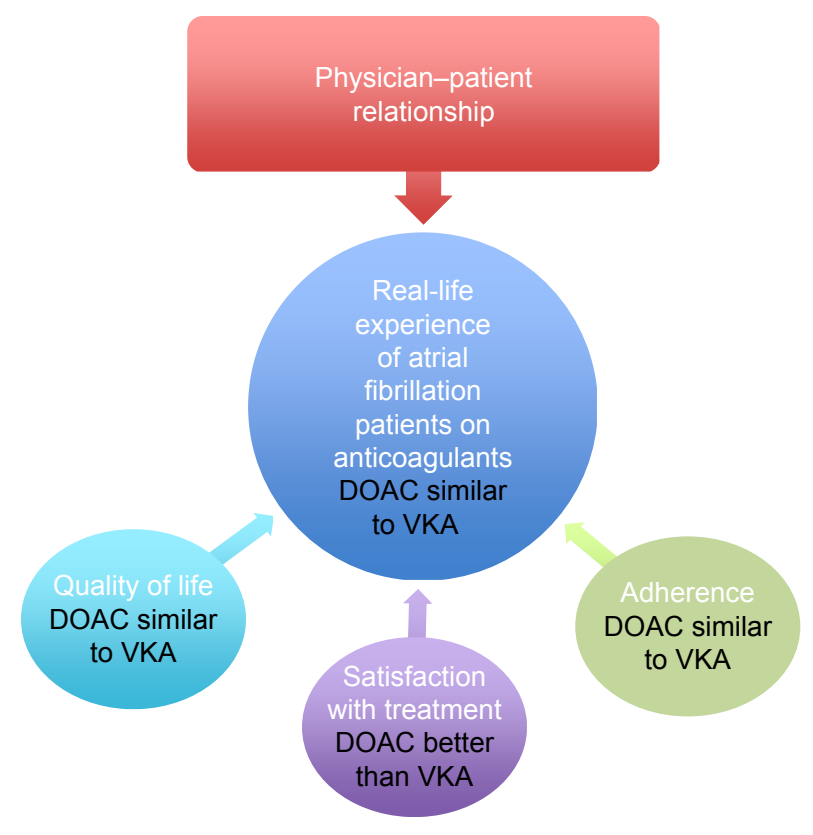

Figure 5 Real life experience of patients with atrial fibrillation on oral anticoagulants: quality of life, satisfaction, and adherence.

Abbreviations: DOAC, direct oral anticoagulant; VKA, vitamin $\mathrm{K}$ antagonists.

entail a real dialog and two-way exchange of information and preferences.

For example, a study was conducted in Amsterdam including 120 patients, to investigate why AF patients preferred DOAC to their usual VKA treatment (36): 57\% would switch to a drug not requiring iterative biological surveillance and $65 \%$ to a drug that induces less bleeding; improved efficacy with DOAC, on the other hand, was less crucial.

\section{Conclusion}

There were no previous real-life studies of AF patients' experience with oral anticoagulation therapy. The three complementary parameters assessed in the present study (quality of life, satisfaction with treatment, and adherence) revealed generally satisfactory experience, whether of VKA or DOAC. However, satisfaction with treatment was greater with DOAC, although this did not improve quality of life or adherence, which was identical with DOAC or VKA (Figure 5).

The supposed greater ease of use of DOAC, reflected in greater satisfaction, did not improve adherence or quality of life. The introduction of DOACs, intended to simplify follow-up for the physician, may have had the collateral effect of making the prescription of oral anticoagulants more complicated. The physician-patient relationship becomes crucial: the physician's attention to the patient's treatment expectations can have a positive impact on the patient's experience.

\section{Acknowledgment}

The MMAS (8-item) content, names, and trademarks are protected by US copyright and trademark laws. Permission for use of the scale and its coding is required. A license agreement is available from Donald E Morisky, ScD, ScM, MSPH, 14725 NE 20th St Bellevue, WA 98007, USA; dmorisky@gmail.com.

\section{Disclosure}

The authors report no conflicts of interest in this work.

\section{References}

1. European Heart Rhythm Association, European Association for CardioThoracic Surgery, Camm AJ, Kirchhof P, Lip GY, et al. Guidelines for the management of atrial fibrillation: the Task Force for the Management of Atrial Fibrillation of the European Society of Cardiology (ESC). Eur Heart J. 2010;31(19):2369-2429.

2. Wolf PA, Abbott RD, Kannel WB. Atrial fibrillation as an independent risk factor for stroke: the Framingham Study. Stroke. 1991;22(8): 983-988.

3. Penado S, Cano M, Acha O, Hernández JL, Riancho JA. Atrial fibrillation as a risk factor for stroke recurrence. Am J Med. 2003;114(3): 206-210.

4. Stewart S, Hart CL, Hole DJ, McMurray JJ. A population-based study of the long-term risks associated with atrial fibrillation: 20-year follow-up of the Renfrew/Paisley study. Am J Med. 2002;113(5):359-364.

5. Hart RG, Pearce LA, Aguilar MI. Meta-analysis: antithrombotic therapy to prevent stroke in patients who have nonvalvular atrial fibrillation. Ann Intern Med. 2007;146(12):857-867.

6. Connolly SJ, Ezekowitz MD, Yusuf S, et al; RE-LY Steering Committee and Investigators. Dabigatran versus warfarin in patients with atrial fibrillation. N Engl J Med. 2009;361(12):1139-1151.

7. Patel MR, Mahaffey KW, Garg J, et al; ROCKET AF Investigators. Rivaroxaban versus warfarin in nonvalvular atrial fibrillation. $N$ Engl J Med. 2011;365(10):883-891.

8. Easton JD, Lopes RD, Bahit MC, et al; ARISTOTLE Committees and Investigators. Apixaban compared with warfarin in patients with atrial fibrillation and previous stroke or transient ischaemic attack: a subgroup analysis of the ARISTOTLE trial. Lancet Neurol. 2012;11(6):503-511.

9. Giugliano RP, Ruff CT, Braunwald E, et al; ENGAGE AF-TIMI 48 Investigators. Edoxaban versus warfarin in patients with atrial fibrillation. N Engl J Med. 2013;369(22):2093-2104.

10. Monz BU, Connolly SJ, Korhonen M, Noack H, Pooley J. Assessing the impact of dabigatran and warfarin on health-related quality of life: results from an RE-LY sub-study. Int J Cardiol. 2013;168(3):2540-2547.

11. Alegret JM, Viñolas X, Arias MA, et al. New oral anticoagulants vs vitamin $\mathrm{K}$ antagonists: benefits for health-related quality of life in patients with atrial fibrillation. Int J Med Sci. 2014;11(7):680-684.

12. HAS. Fibrillation Atriale HAS 2014. Available from: http://www.hassante.fr/portail/upload/docs/application/pdf/2014-05/guide_pds_fibrillation_atriale_vf.pdf. Accessed September 12, 2017.

13. Chevalier J, de Pouvourville G. Valuing EQ-5D using time trade-off in France. Eur J Health Econ. 2013;14(1):57-66.

14. Prins MH, Marrel A, Carita P, et al. Multinational development of a questionnaire assessing patient satisfaction with anticoagulant treatment: the "Perception of Anticoagulant Treatment Questionnaire" (PACT-Q). Health Qual Life Outcomes. 2009;7:9.

15. Morisky DE, Ang A, Krousel-Wood M, Ward H. Predictive validity of a medication adherence measure in a patient setting. J Clin Hyper. 2008;10(5):348-354.

16. Prins $\mathrm{MH}$, Guillemin I, Gilet $\mathrm{H}$, et al. Scoring and psychometric validation of the Perception of Anticoagulant Treatment Questionnaire (PACT-Q). Health Qual Life Outcomes. 2009;7:30. 
17. Morisky DE, DiMatteo MR. Improving the measurement of selfreported medication nonadherence: Final response. J Clin Epidem. 2011; 64:258-263.

18. Morisky DE, Green LW, Levine DM. Concurrent and predictive validity of a self-reported measure of medication adherence. Med Care. 1986; 24(1):67-74.

19. Krousel-Wood MA, Islam T, Webber LS, Re RS, Morisky DE, Muntner P. New medication adherence scale versus pharmacy fill rates in seniors with hypertension. Am J Manag Care. 2009; 15(1):59-66.

20. Wang Y, Kong MC, Ko Y. Psychometric properties of the 8-item Morisky Medication Adherence Scale in patients taking warfarin. Thromb Haemost. 2012;108(4):789-795.

21. Camm AJ, Amarenco P, Haas S, et al; XANTUS Investigators. XANTUS: a real-world, prospective, observational study of patients treated with rivaroxaban for stroke prevention in atrial fibrillation. Eur Heart J. 2016;37(14):1145-1153.

22. Kakkar AK, Mueller I, Bassand JP, et al; GARFIELD Registry Investigators. Risk profiles and antithrombotic treatment of patients newly diagnosed with atrial fibrillation at risk of stroke: perspectives from the international, observational, prospective GARFIELD registry. PLoS One. 2013;8(5):e63479.

23. Huisman MV, Rothman KJ, Paquette M, et al; GLORIA-AF Investigators. Antithrombotic treatment patterns in patients with newly diagnosed nonvalvular atrial fibrillation: the GLORIA-AF registry, phase II. Am J Med. 2015;128(12):1306-1313.e1.

24. Le Heuzey JY, Ammentorp B, Darius H, et al. Differences among western European countries in anticoagulation management of atrial fibrillation. Data from the PREFER IN AF registry. Thromb Haemost. 2014;111(5):833-841.

25. RuffCT, Giugliano RP, Braunwald E, et al. Comparison of the efficacy and safety of new oral anticoagulants with warfarin in patients with atrial fibrillation: a meta-analysis of randomised trials. Lancet. 2014; 383(9921):955-962.

26. Brüggenjürgen B, Schliephacke T, Darius H, et al. Treatment satisfaction in patients with atrial fibrillation on new oral anticoagulants as assessed with PACT-Q2 at baseline and 12-month follow-up: prefer in Af registry. Value Health. 2014;17(7):A497.
27. Apostolakis S, Lane DA, Guo Y, Buller H, Lip GY. Performance of the HEMORR(2)HAGES, ATRIA, and HAS-BLED bleeding riskprediction scores in patients with atrial fibrillation undergoing anticoagulation: the AMADEUS (evaluating the use of SR34006 compared to warfarin or acenocoumarol in patients with atrial fibrillation) study. J Am Coll Cardiol. 2012;60(9):861-867.

28. Nieuwlaat R, Capucci A, Camm AJ, et al; European Heart Survey Investigators. Atrial fibrillation management: a prospective survey in ESC member countries: the Euro Heart Survey on Atrial Fibrillation. Eur Heart J. 2005;26(22):2422-2434.

29. Liard F, Le Heuzey JY, Aliot E, Mabo P, Leenhardt A. [Atrial fibrillation and anticoagulation: general practitioner, cardiologist and patient's points of view]. Presse Méd. 2013;42(7-8):e259-e270. French.

30. Marvig CL, Verhoef TI, de Boer A, et al; EU-PACT consortium. Quality of life in patients with venous thromboembolism and atrial fibrillation treated with coumarin anticoagulants. Thromb Res. 2015;136(1): 69-75.

31. Castellucci LA, Shaw J, van der Salm K, et al. Self-reported adherence to anticoagulation and its determinants using the Morisky medication adherence scale. Thromb Res. 2015;136(4):727-731.

32. Horstmann S, Rizos T, Saribas M, Efthymiou E, Rauch G, Veltkamp R. Cognitive impairment is not a predictor of failure to adhere to anticoagulation of stroke patients with atrial fibrillation. Cerebrovasc Dis. 2015;39(5-6):325-331.

33. Kneeland PP, Fang MC. Current issues in patient adherence and persistence: focus on anticoagulants for the treatment and prevention of thromboembolism. Patient Prefer Adherence. 2010;4:51-60.

34. Légaré F, Witteman HO. Shared decision making: examining key elements and barriers to adoption into routine clinical practice. Health Aff (Millwood). 2013;32(2):276-284.

35. Palacio AM, Kirolos I, Tamariz L. Patients values and preferences when choosing anticoagulants. Patient Prefer Adherence. 2015;9: $133-138$.

36. Boom MS, Berghuis EM, Nieuwkerk PT, Pinedo S, Büller HR. When do patients prefer a direct oral anticoagulant over a vitamin $\mathrm{K}$ antagonist? Neth J Med. 2015;73(8):368-372.
Patient Preference and Adherence

\section{Publish your work in this journal}

Patient Preference and Adherence is an international, peer-reviewed, open access journal that focuses on the growing importance of patient preference and adherence throughout the therapeutic continuum. Patient satisfaction, acceptability, quality of life, compliance, persistence and their role in developing new therapeutic modalities and compounds to optimize

\section{Dovepress}

clinical outcomes for existing disease states are major areas of interest for the journal. This journal has been accepted for indexing on PubMed Central. The manuscript management system is completely online and includes a very quick and fair peer-review system, which is all easy to use. Visit http://www. dovepress.com/testimonials.php to read real quotes from published authors. 